American Journal of Pharmaceutical Education 2021; 85 (2) Article 8471.

\title{
COMMENTARY
}

\section{The Power of Peer Mentoring to Support Women Pharmacy Faculty Personally and Professionally}

\author{
Lauren Biehle, PharmD, ${ }^{\mathrm{a}}$ Ashley Crowl, PharmD, ${ }^{\mathrm{b}}$ Helen C. Park, PharmD, ${ }^{\mathrm{c}}$ Susan Vos, PharmD, ${ }^{\mathrm{d}}$ \\ Amy M. Franks, PharmD ${ }^{\text {e,f }}$ \\ ${ }^{a}$ University of Wyoming School of Pharmacy, Laramie, Wyoming \\ ${ }^{\mathrm{b}}$ University of Kansas School of Pharmacy, Lawrence, Kansas \\ ${ }^{\mathrm{c}}$ Roseman University of Health Sciences, Henderson, Nevada \\ d The University of Iowa College of Pharmacy, Iowa City, Iowa \\ ${ }^{\mathrm{e}}$ University of Arkansas for Medical Sciences College of Pharmacy, Little Rock, Arkansas \\ ${ }^{\mathrm{f}}$ Editorial Board Member, American Journal of Pharmaceutical Education, Arlington, Virginia
}

Submitted November 12, 2020; accepted November 17, 2020; published February 2021.

\begin{abstract}
Regardless of a faculty member's career stage, effective mentoring is critical for successful professional development and a thriving academic career. Traditional mentor-mentee relationships can be effective but may present challenges for some faculty depending on their individual needs and institutional resources. The use of peer mentoring circles, where group members serve as both mentor and mentee, may provide additional resources and benefits to faculty at all career stages and appear especially beneficial for women faculty because of their focus on interconnectedness and collaboration. However, literature is scarce regarding effective mentoring strategies for women pharmacy faculty. As members of one women faculty-only peer mentoring circle, we describe our experiences using this mentoring strategy and offer recommendations for other faculty members considering this approach.
\end{abstract}

Keywords: mentoring, peer mentoring circles, faculty development, women faculty

\section{INTRODUCTION}

Mentoring provides many benefits to both the mentor and mentee. ${ }^{1,2}$ Formal mentoring programs have demonstrated increased satisfaction, dedication, communication, confidence, support of diversity, teaching effectiveness, retention, and increased productivity. ${ }^{1,2}$ Without mentoring, faculty report increased feelings of stress, isolation, and burnout. ${ }^{2}$ The American Association of Colleges of Pharmacy (AACP) Joint Council on Mentorship Taskforce developed a checklist for mentorship programs in $2014 .^{2}$ In the taskforce's report, Law and colleagues recommended against a rigid, one-size-fits-all mentorship program as mentors and mentees differ in their needs, timeline, and approach to goals. ${ }^{2}$ Specifically, women faculty face unique barriers in professional development and career promotion, including lack of mentoring, childcare needs, less national recognition, and less-aggressive negotiating skills. ${ }^{3}$ For example, the majority $(51.2 \%)$ of full-time pharmacy faculty identify as women, yet men represent most positions of upper

Corresponding Author: Amy M. Franks, University of

Arkansas for Medical Sciences College of Pharmacy, $4301 \mathrm{~W}$. Markham St., \#522, Little Rock, AR 72205. Tel: 501-296-

1296. Email: afranks@uams.edu leadership, with women faculty filling a minority of dean $(23 \%)$, associate dean $(48 \%)$, and professor $(35 \%)$ roles. $^{4}$ This disparity may suggest that the professional development needs of women faculty are not being met. Nonetheless, there is limited data describing effective mentoring strategies specific to women faculty in pharmacy.

Peer mentoring circles, where individuals serve as both mentor and mentee, may lend additional benefits over traditional mentor-mentee relationships. ${ }^{5}$ These mentoring circles promote an added element of humility among members and a positive leveling effect because each member has something to give and something to gain from the relationship. Furthermore, by curating members with different backgrounds and areas of specialty, this effect is compounded in that each member is a specialist in their respective areas. Peer mentoring circles remove the traditional levels of hierarchy and recognize each member as a unique contributor. Removing these barriers allows members to fluidly alternate in their roles as mentor and mentee, thus maximizing the benefits from the mentoring circle relationship. Peer mentoring circles provide a support system while empowering members to serve as a sounding board for each other. ${ }^{5}$ 


\section{American Journal of Pharmaceutical Education 2021; 85 (2) Article 8471.}

Understanding that women faculty face issues such as gender stereotypes, organizational barriers (eg, glass ceilings), and pressure to choose between family and career, gender concordance among peer mentoring circles may help establish a united support system. ${ }^{6}$ While diversity in backgrounds and dual roles as both mentor and mentee contribute to a positive environment that enables both giving and receiving, the shared experiences and challenges faced by women pharmacy faculty provide a common thread by which to launch a successful peer mentoring circle. In this commentary, we explore literature on peer mentoring, describe our own experience in a women-only faculty peer mentoring circle, and share recommendations for other successful peer mentoring circles.

\section{DISCUSSION}

\section{Impact of Peer Mentoring Circles}

Pololi and colleagues outlined the theoretical foundations of peer mentoring circles as individual aspirations, small group dynamics, learning via relationships and support, mindfulness and self-awareness, finding meaning in work, strengths-based leadership, and nonhierarchical relationships. ${ }^{7}$ The benefits of peer mentoring circles may be particularly advantageous by limiting relational aspects, such as intergenerational conflict, ineffective communication, and incompatible personalities. $^{7-9}$ Peer mentoring also encourages supportive relationships and the opportunity to give and receive feedback in a more comfortable setting. ${ }^{9}$ Fleming and colleagues described a peer mentoring program among medical faculty in a large department of pediatrics that resulted in significantly increased knowledge, skills, and abilities in professional development and scholarship among junior faculty. The majority of participants were women (66\%), and the changes were significantly higher among women medicine faculty than among their male colleagues. ${ }^{10}$ Additionally, peer mentoring circles may address the evolving needs of faculty throughout the stages of their career, providing support for promotion preparation, idea generation, scholarship, and conflict resolution. $^{2,11}$

Peer mentoring circles may specifically appeal to women faculty for several reasons. Peer mentoring circles encourage a feeling of interpersonal connectedness. Files and colleagues theorized that this feeling may encourage women in particular, as they tend to respond to group achievement over individual achievement. ${ }^{6}$ In this setting, women faculty may be more likely to discuss clinical practice demands and challenges of personal lives in a peer mentoring circle of other women. ${ }^{6}$ Women participants may share deeply emotional situations, which can lead to an increased sense of belonging and connectedness among members. ${ }^{12}$ Further, the collaborative nature of peer mentorship circles offer support from members with diverse experiences and backgrounds, which can lead to a variety of proposed solutions and suggestions for the mentee. ${ }^{12}$ Varkey and colleagues reported improvements in satisfaction, medical literature search skills, ability to write a review, and ability to critically evaluate medical literature among medical faculty participants in a women faculty peer mentoring circle. ${ }^{13}$ Female faculty may also have a greater interest in collaboration when compared to male faculty. ${ }^{14}$ Carr and colleagues reported that female medical faculty were enthusiastic about the process of collaboration and the interpersonal relationships involved, whereas male faculty were more focused on pragmatic outcomes of the collaboration. ${ }^{15}$

\section{Development of the Wonder Women Peer Mentoring Circle}

In 2019, the AACP Women Faculty Special Interest Group invited its members to participate in networking using the strategy of peer mentoring circles based on Sheryl Sandberg's book Lean In: Women, Work, and the Will to Lead. ${ }^{16}$ The purpose of these circles was to foster personal and professional development of women in pharmacy academia that would allow participants a venue to share, learn, gain insights, and develop their network. The committee gave general guidance to each circle, but the specific details and function was left to the circle members.

Our peer mentoring circle was formed from this invitation and includes seven women faculty from seven institutions and various academic ranks (one assistant professor, four associate professors, and two professors). Additionally, two members hold assistant/associate dean positions and one is a department chair. During our initial meeting, we introduced our professional roles and affiliations and shared our professional and personal interest areas. We established the monthly frequency of our meetings and agreed to meet via video conference. We also identified a coordinator to manage logistics, but agreed that all members would be active participants. We established the following ground-rules: all discussions would be confidential; understanding would be expressed towards members if they could not attend a meeting, and the main goal of our circle would be to provide support and resources for each other. Based on that group dynamic and that the members collectively identified as women leaders, we affectionately named our circle the "Wonder Women."

Following our initial meeting, we created a shared cloud-based folder to house a list of topic discussion 


\section{American Journal of Pharmaceutical Education 2021; 85 (2) Article 8471.}

ideas, a schedule of facilitators for each meeting, and other resources. We wanted our meetings to be uplifting and helpful rather than adding work or stress, so there were minimal preparatory requirements for leading or participating in the meeting. For example, the facilitator could prepare a topic beforehand and send out suggested pre-work, or they could pose a question/scenario during the meeting. Members were encouraged to attend, with or without advanced preparation. Though the circle discussed several books, ${ }^{17-19}$ members were not required to read the texts in advance. Table 1 provides topics discussed during the circle's first year.

As the peer mentoring circle sign-up was voluntary, we believe that all of our members were genuinely invested in helping our group be successful. To gain further insight into why our circle was successful, several members of our circle answered open-ended questions as shown in Table 2.

\section{Recommendations for Peer Mentoring Circles}

Through reflection and discussion, we have identified characteristics and practices of our peer mentoring circle that have contributed to its success. From these attributes, we have developed recommendations for other faculty peer mentoring circles. Among these important considerations are group makeup, prioritization of trusting relationships and a supportive environment, and wellorganized logistics to support professional development needs.

We recommend careful consideration of peer mentoring circle member makeup according to gender, geographic location, and faculty responsibilities. One of the most valued characteristics of our peer mentoring circle is its composition as a women-only circle. Consequently, we gained comfort and familiarity with each other more quickly than what may have resulted from a mixed-gender circle. We immediately connected through sharing life and professional experiences frequently encountered by professional women, such as workplace environment challenges and balancing work and professional responsibilities with leisure or family activities. Although we recognize that male professionals also encounter challenges, the issues of concern are likely different and not as readily relatable among members of mixed-gender mentoring groups. ${ }^{20} \mathrm{We}$ also strongly recommend peer mentoring circles be formed with members from different institutions, academic ranks, and responsibilities. As faculty from seven separate institutions, our peer mentors were not familiar with our policies or colleagues at our institution, and we thus avoided political challenges that might occur with mentors at our home institutions. ${ }^{20}$ Our diverse makeup of faculty from all academic ranks and both administrative and non-administrative leaders led to fruitful conversations offering a variety of points of view that may not be possible when members are more uniform in their responsibilities or experiences (eg, all department chairs).

Second, we recommend thoughtful attention to establishing relationships of trust and accountability immediately upon formation of the peer mentoring circle. To do this, we recommend that members resist the urge to jump right in to discussing mentoring content, but rather spend time getting to know each other, both professionally and personally. Members should practice accountability by prioritizing scheduled meetings, checking in when a member is unable to join a meeting, and commit to engaging in the conversation if a member asks for advice or perspective. Most importantly, members should participate in sessions with open minds, recognizing that no one is the "expert" and all members are both contributing to and learning from discussions. This mutual

Table 1. Topics Discussed by a Women Pharmacy Faculty Peer Mentoring Group in 2019-2020

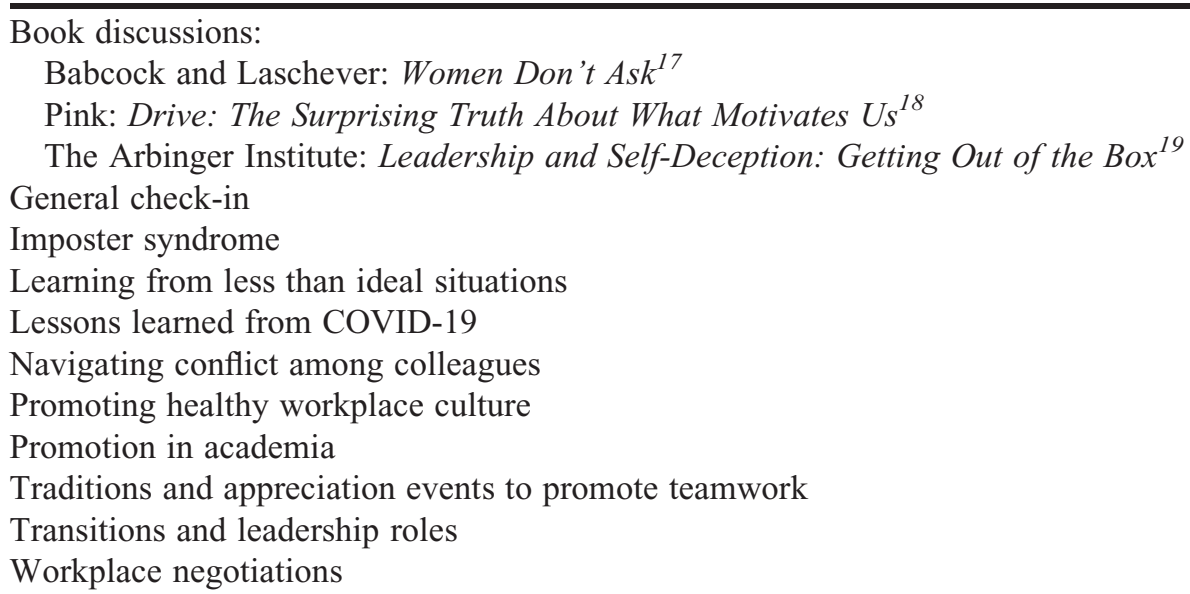




\section{American Journal of Pharmaceutical Education 2021; 85 (2) Article 8471.}

Table 2. Responses from Members of the "Wonder Women” Female Pharmacy Faculty Peer Mentoring Circle to Key Questions

\begin{tabular}{|c|c|}
\hline Question & Member Responses \\
\hline $\begin{array}{l}\text { Why did you respond to the call for } \\
\text { women's peer mentoring circles? }\end{array}$ & $\begin{array}{l}\text { Seeking professional development } \\
\text { Expand support and mentor network } \\
\text { Receive guidance/insight from multiple faculty members } \\
\text { Gain different perspectives of faculty members outside home institution } \\
\text { Comfort with meeting with a group of female peers } \\
\text { Peer mentoring allowed for a more balanced relationship compared to mentor/mentee }\end{array}$ \\
\hline $\begin{array}{l}\text { What challenges did we } \\
\text { experience? }\end{array}$ & $\begin{array}{l}\text { Logistics (eg, scheduling across multiple time zones) } \\
\text { Access to a web camera for online meetings } \\
\text { Needed ramp-up time to get to know each other }\end{array}$ \\
\hline
\end{tabular}

vulnerability is paramount in establishing trust and supports the emphasis on interpersonal and collaborative relationships common to the mentoring preferences and needs of women faculty members. ${ }^{14}$ We recommend these expectations and "ground rules" be formally discussed and/or documented as a way of establishing a supportive environment and group culture. Members who value each other and the integrity of the circle will be more likely to actively participate and continue the success and evolution of the circle.

Finally, a well-organized plan for circle coordination eases burdens on individual members and helps to ensure needs are being met. Consider making both joining and exiting the circle easy by establishing a focus on individuals' needs. If professional development and networking needs are not being met, members should be able to leave without repercussion. Members may be more willing contributors when they participate voluntarily and do not sense external pressure to participate. Peer mentoring circles should also establish their needs for content and balance between more traditional professional development topics (negotiating, dealing with conflict, etc) and ongoing relationship building through less focused conversations. Importantly, our circle allowed for meetings that were only check-ins, especially in times of higher stress, such as during the COVID-19 pandemic.
We also believe it is important that each member takes turns facilitating discussion to emphasize the peer mentoring relationships. If one or two members lead discussions too regularly, group dynamics may be damaged and revert to a more traditional mentor-mentee dyad structure. We recommend assigning one member to serve on a rotating basis as the group's coordinator, with duties such as setting and communicating meeting times and connection information and documenting topics discussed. Circles should schedule meetings and topics in advance to lessen barriers related to multiple time zones and busy schedules. We recommend that circles use available technology to simplify logistics, such as online meeting scheduling tools and platforms for video conferencing.

\section{CONCLUSION}

The relationships developed and nurtured through our peer mentorship have been very rewarding, both personally and professionally. In our experience, peer mentoring circles provide benefits over the traditional dyad form of mentoring. This model of peer mentoring may appeal to and benefit women faculty more than male faculty because of the emphasis on interpersonal connectedness and relatability of experiences. More research is needed to evaluate the outcomes of peer mentoring in academic pharmacy. 


\section{American Journal of Pharmaceutical Education 2021; 85 (2) Article 8471.}

\section{ACKNOWLEDGMENTS}

The authors gratefully acknowledge the officers and networking committee members of the AACP Women Faculty Special Interest Group for their advocacy toward the mentoring of women faculty, as well as their organization of peer mentoring groups.

\section{REFERENCES}

1. Haines SL, Popovich NG. Engaging external senior faculty members as faculty mentors. Am J Pharm Educ. 2014;78(5):Article 101.

2. Law AV, Bottenberg MM, Brozick AH, et al. A checklist for the development of faculty mentorship programs. Am J Pharm Educ. 2014;78(5):Article 98.

3. Blood EA, Ullrich NJ, Hirshfeld-Becker DR, et al. Academic women faculty: are they finding the mentoring they need? $J$ Womens Health. 2012;21(11):1201-1208.

4. American Association of Colleges of Pharmacy. 2019-20 profile of pharmacy faculty. https://www.aacp.org/research/pharmacyfaculty-demographics-and-salaries. Accessed February 4, 2021.

5. Smith JO, Whitman JS, Grant PA, Stanutz A, Russett JA, Rankin $\mathrm{K}$. Peer networking as a dynamic approach to supporting new faculty. Innov High Educ. 2001;25(3):197-207.

6. Files JA, Blair JE, Mayer AP, Ko MG. Facilitated peer mentorship: a pilot program for academic advancement of female medical faculty. J Womens Health. 2008;17(6):1009-1015.

7. Pololi LH, Evans AT. Group peer mentoring: an answer to the faculty mentoring problem? A successful program at a large academic department of medicine. J Contin Educ Health Prof. 2015; 35(3):192-200.

8. Darwin A, Palmer E. Mentoring circles in higher education. High Educ Res Dev. 2009;28(2):125-136.

9. Prendergast HM, Heinert SW, Erickson TB, Thompson TM, Vanden Hoek TL. Evaluation of an enhanced peer mentoring program on scholarly productivity and promotion in academic emergency medicine: a five-year review. J Natl Med Assoc. 2019; 111(6):600-605.

10. Fleming GM, Simmons JH, Xu M, et al. A facilitated peer mentoring program for junior faculty to promote professional development and peer networking. Acad Med. 2015;90(6): 819-826.

11. Erlich DR, Cohen-Osher MB, Goodell KH. 'We rise by lifting others': peer support and professional development for women in academic medicine. Educ Prim Care. 2017;28(5): 291-294.

12. Levy-Tzedek S, Moran GS, Alon U, Sal-Man N. Peer power: a women's peer-mentoring program at the workplace: example from the academia. EMBO Rep. 2018;19(12).

13. Varkey P, Jatoi A, Williams A, et al. The positive impact of a facilitated peer mentoring program on academic skills of women faculty. BMC Med Educ. 2012;12:14.

14. Mayer AP, Blair JE, Ko MG, Patel SI, Files JA. Long-term follow-up of a facilitated peer mentoring program. Med Teach. 2014; 36(3):260-266.

15. Carr PL, Pololi L, Knight S, Conrad P. Collaboration in academic medicine: reflections on gender and advancement. Acad Med. 2009; 84(10):1447-1453.

16. Sandberg S. Lean In: Women, Work, and the Will to Lead. New York, NY: Random House, Inc.; 2013.

17. Babcock L, Laschever S. Women Don't Ask. New York, NY: Bantam Dell; 2007.

18. Pink D. Drive: The Surprising Truth About What Motivates Us. New York, NY: Riverhead Books; 2011.

19. The Arbinger Institute. Leadership and Self-Deception: Getting Out of the Box. 2nd edition. San Francisco, CA: Berrett-Koehler Publishers, Inc.; 2015.

20. Gibson SK. Mentoring of women faculty: the role of organizational politics and culture. Innov High Educ. 2006;31(1): 63-79. 